\title{
Postmortem water contents of major organs with regard to the cause of death
}

\section{Naoto Tani, Tomoya Ikeda, Alissa Shida, Yayoi Aoki, Shigeki Oritani, Takaki Ishikawa}

\begin{tabular}{|c|c|}
\hline Citation & Journal of Forensic and Legal Medicine, $65 ; 48-54$ \\
\hline Issue Date & 2019-07 \\
\hline Type & Journal Article \\
\hline Textversion & Author \\
\hline Right & $\begin{array}{l}\text { (C) } 2019 \text { Elsevier Ltd and Faculty of Forensic and Legal Medicine. This manuscript } \\
\text { version is made available under the CC-BY-NC-ND } 4.0 \text { License. } \\
\text { https://creativecommons.org/licenses/by-nc-nd/4.0/. } \\
\text { This is the accepted manuscript version. Please cite only the published version. The } \\
\text { article has been published in final form at https://doi.org/10.1016/j.jflm.2019.05.003. }\end{array}$ \\
\hline DOI & 10.1016/j.jflm.2019.05.003 \\
\hline Highlights & $\begin{array}{l}\text {-We investigated the tissue water contents of the lungs, brain, kidneys, and spleen. } \\
\cdot \text { We evaluated the relationship between tissue water content and cause of death. } \\
\text { - Tissue water content is useful to distinguish saltwater and freshwater drowning. } \\
\text { - Tissue water content is useful for the pathophysiology of circulatory failure. }\end{array}$ \\
\hline
\end{tabular}

Self-Archiving by Author(s)

Placed on: Osaka City University Repository

TANI N, IKEDA T, SHIDA A, AOKI Y, ORITANI S, \& ISHIKAWA T. (2019). Postmortem water contents of major organs with regard to the cause of death. Journal of Forensic and Legal Medicine. 65, 48-54. DOI:10.1016/j.jflm.2019.05.003 


\section{Postmortem water contents of major organs with regard to the cause of death}

Tani Naoto ${ }^{\mathrm{a}, \mathrm{b}^{*}}$, Tomoya Ikeda ${ }^{\mathrm{a}, \mathrm{b}}$, Alissa Shida ${ }^{\mathrm{a}}$, Yayoi Aoki ${ }^{\mathrm{a}}$, Shigeki Oritani ${ }^{\mathrm{a}}$, Takaki Ishikawa ${ }^{\mathrm{a}, \mathrm{b}}$

a Department of Legal Medicine, Osaka City University Medical School, Asahi-machi 1-4-3, Abeno, 545-8585 Osaka, Japan

${ }^{b}$ Forensic Autopsy Section, Medico-legal Consultation and Postmortem Investigation Support Center, c/o Department of Legal Medicine, Osaka City University Medical School, Asahi-machi 1-4-3, Abeno, 545-8585, Osaka, Japan

*Corresponding author

Naoto Tani

Department of Legal Medicine, Osaka City University Medical School, Asahi-machi 1-4-3, Abeno, Osaka, 545-8585 Japan

Tel.: +81-6-6645-3767

Fax: +81-6-6634-3871

E-mail: tani.naoto@med.osaka-cu.ac.jp 


\begin{abstract}
The water contents of individual organs are maintained in a narrow range, but altered in morbidity owing to a disturbance of water equilibrium. The present study investigated the tissue water contents of major organs with regard to the cause of death in serial autopsy cases within 3 days postmortem ( $\mathrm{n}=329 ; 223$ males, 106 females; age range, 1-100 years). Individual tissue water contents differed markedly across organs, but no significant postmortem or survival-period dependence, gender-related difference, or age dependence was observed. However, the lung water contents were higher in drowning cases, especially in saltwater cases $(p<0.05)$, and in strangulation among the acute mechanical asphyxiation cases. The brain water contents were higher in hypothermia cases (cold exposure) and tended to be higher in hyperthermia cases (heatstroke). The kidney water contents were higher in drowning and acute cardiac cases than in fatal intoxication and fire fatality cases, but tended to be higher in fresh- and bathwater drowning cases than in saltwater cases $(p>0.05)$. The spleen water contents were higher in bathwater drowning than in saltwater and freshwater cases, but did not differ among other the causes of death. These findings suggest that the postmortem tissue water content of individual organs, especially the lungs and/or kidney, depends on the cause of death and particularly contributes to differentiation between saltwater and freshwater drowning, respectively. This work therefore provides insight into the investigation of varied tissue water imbalances during the death process. In conclusion, we recommend the measurement of tissue water content because it is easy to perform and appears to be useful for evaluating the pathophysiology of systemic circulatory failure.
\end{abstract}

Keywords: Pathophysiology, Tissue water content, Edema, Drowning, Hypoxia/ischemia, Circulatory failure 


\section{Graphical abstract}

(\%) (a) Upper lobe of the lung
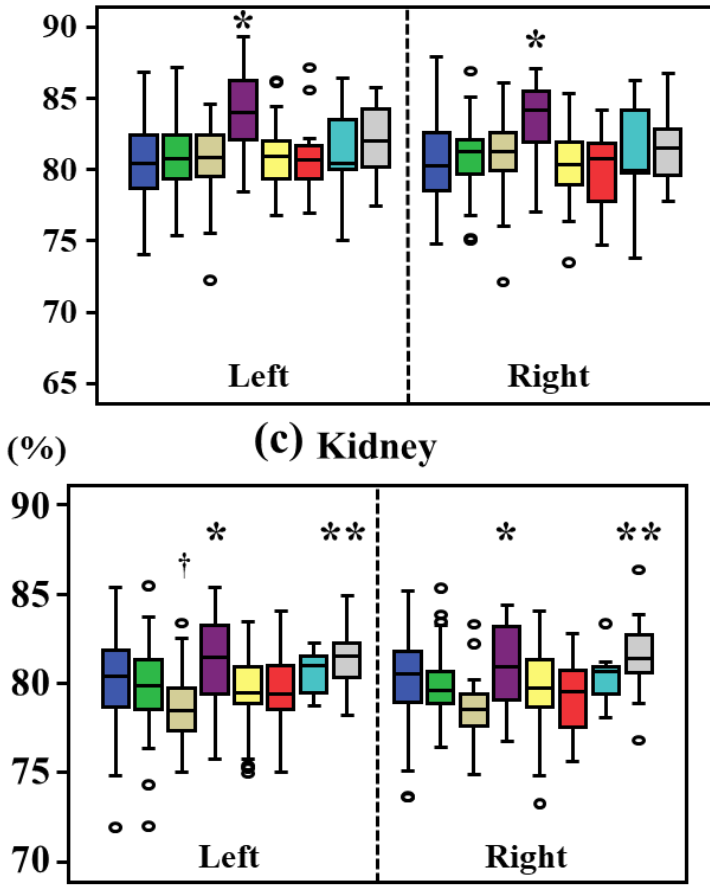

$\square$ Injury Asphyxia $\square$ Intoxication Drowning
(\%)

(b) Lower lobe of the lung

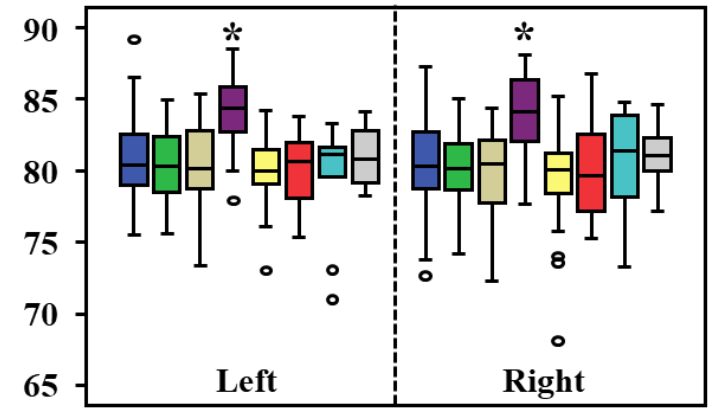

(\%)

(d) Brain

(\%)

(e) Spleen
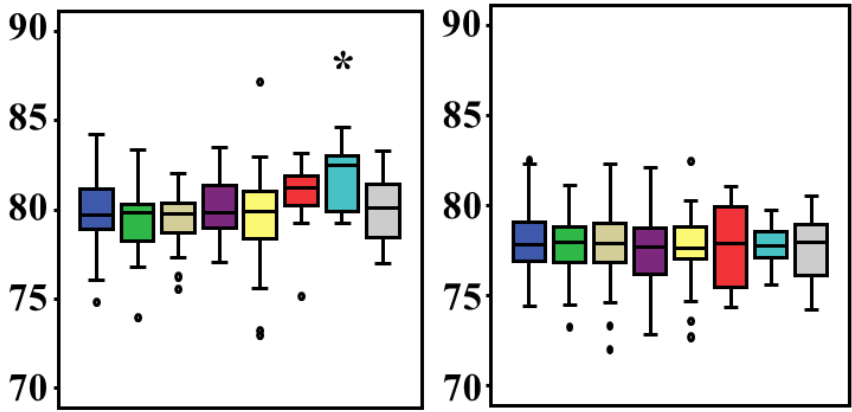

Fire fatality $\square$ Hypothermia

Hyperthermia $\square$ Acute cardiac death

Water contents with regard to the cause of death in the upper lobes of the lung (a), lower lobes of lung (b), kidney (c), brain (d), spleen (e). 


\section{Highlights}

- We investigated the tissue water contents of the lungs, brain, kidneys, and spleen.

- We evaluated the relationship between tissue water content and cause of death.

- Tissue water content is useful to distinguish saltwater and freshwater drowning.

- Tissue water content is useful for the pathophysiology of circulatory failure. 


\section{Introduction}

The tissue water content (TWC) of individual human organs are generally stable and maintained as part of the whole-body water-electrolyte equilibrium that involves both water intake and renal excretion. ${ }^{1}$ Fatal trauma or disease can cause organ-specific and/or systemic water imbalances, which present as visceral edemas in autopsy, often in the lungs and brain, ${ }^{2-4}$ which are reportedly caused by the activation of humoral regulation and/or more regulatory mechanisms. In addition, Starling forces govern the passive exchange of water between capillary microcirculation and interstitial fluid; therefore, abnormal Starling forces such as increased venous capillary pressure and decreased plasma oncotic pressure promote fluid extravasation and edema formation. ${ }^{5}$ Previous forensic studies have demonstrated that the postmortem lung weight depends strongly on the cause of death and survival time, which are associated with the development of pulmonary congestion and edema. ${ }^{6,7}$ Moreover, the severity of brain edema is typically related to the brain weight. ${ }^{8}$ Other organs, including the spleen and kidney, may also cause tissue edema owing to water imbalance. ${ }^{9}$ Recent studies have suggested that molecular pathology should be applied to investigate tissue edema, ${ }^{2-4}$ and quantitative analyses of water contents and their distribution by postmortem computed tomography are used to diagnose pulmonary congestion and edema. ${ }^{10,11}$ However, these studies remain rare, especially as they apply to the relationship between TWC and the cause of death.

Although the association between organ weight and TWC has been investigated, ${ }^{6-8}$ to our knowledge, no consensus has been reached on their relationship, and it remains unclear whether organ weight can be applied to the evaluation of edema in forensic autopsy cases. Furthermore, other than organ weight, no quantitative indicators are available to connect the effects of variation 
in the TWC and the cause of death. ${ }^{12}$ In the clinical medicine field, hematocrit is used to measure the ratio of erythrocyte flow to total blood flow. When the organs absorb water from the blood, hematocrit is expected to increase ${ }^{13}$; however, to our knowledge, no previous reports have evaluated this relationship using an autopsy sample.

In the present study, we investigated the relationship between TWC, organ weight, and hematocrit and evaluated the TWC of the lungs, brain, kidneys, and spleen among deceased individuals as a possible quantitative indicator of the pathophysiology of systemic water dynamics.

\section{Material and methods}

\subsection{Samples}

Serial autopsy cases examined within 3 days postmortem at our institution over the previous 8 years were analyzed. To minimize the possibility of bias, we examined all cases in which TWC could be measured, except for cases of natural death (excluding sudden cardiac death). Furthermore, in the present study, only clearly accountable cases were collected. In total, there were 329 cases (223 males and 106 females; median age, 63 years; age range $0-100$ years). The causes of death were classified based on a complete autopsy and macromorphological, micropathological, and toxicological examinations as follows: injury (head blunt injury: $n=39$; non-head blunt injury: $\mathrm{n}=32$; sharp instrument injury: $\mathrm{n}=21$ ), asphyxia (hanging: $\mathrm{n}=17$; strangulation: $\mathrm{n}=16$; others: $\mathrm{n}=14$ ), fatal intoxication (methamphetamines: $\mathrm{n}=13$; psychotropics: $\mathrm{n}=9$; others: $\mathrm{n}=5$ ), drowning (saltwater: $\mathrm{n}=10$; freshwater: $\mathrm{n}=9$; bathtub: $\mathrm{n}=13$ ), fire fatality

(including cases with low $[<30 \%]$, intermediate $[30-60 \%]$, and high $[>60 \%]$ carboxyhemoglobin [CO-Hb] levels; $\mathrm{n}=38, \mathrm{n}=24$, and $\mathrm{n}=15$, respectively), hyperthermia (heat stroke: $\mathrm{n}=16$ ), 
hypothermia (cold exposure: $\mathrm{n}=9$ ), and acute cardiac death $(\mathrm{n}=29)$, which included acute myocardial ischemia without hemopericardium and other cardiac diseases. The hypothermia and hyperthermia cases involved cold and hot weather, respectively, at night or during the day, and the diagnosis was based on pathology and toxicology that considered circumstantial evidence, excluding other causes of death. The approximate survival time ranged from $0.5 \mathrm{~h}$ to 2 months (median, $0.5 \mathrm{~h}$ ). The detailed case profiles are shown in Tables 1 . The postmortem interval was defined as the time from the estimated time of death to the autopsy. The survival time was defined as the period from the onset of the fatal insult to death. All data, including organ weight, were collected from autopsy records. Tissue specimens were taken from consistent sites at autopsy as follows: The upper and lower lobes of the bilateral lungs, the left parietal lobe of the brain, the bilateral kidneys, and the spleen. These tissue specimens were stored at $4{ }^{\circ} \mathrm{C}$ in a refrigerator until use within $24 \mathrm{~h}$.

\subsection{TWC measurements}

The TWC of the specimens was measured using a halogen moisture analyzer (model HB43, Halogen; Mettler Toledo International, Tokyo, Japan) and presented as the ratio (\%) of the difference between the wet weight (WW) and the dry weight (DW) after the tissue samples were dried at $150{ }^{\circ} \mathrm{C}$ for $30 \min (\mathrm{TWC}=(\mathrm{WW}-\mathrm{DW}) / \mathrm{WW} \times 100) .{ }^{4}$

\subsection{Blood analysis}

Bilateral heart blood hematocrit values were measured by flow cytometry using an automated hematology analyzer (SE-9000 ${ }^{\mathrm{TM}}$; Sysmex Co., Ltd., Kobe, Japan) within 24 h after sampling. ${ }^{14}$ 


\subsection{Statistical analysis}

Statistical analyses were performed using SPSS (version 17.0; SPSS, Inc., Chicago, IL, USA). We used linear regression to examine the relationships between pairs of parameters. The MannWhitney $U$ test was performed to assess differences between groups, and the Kruskal-Wallis test was conducted to determine differences among groups. In this report, graphs are presented as box and whisker plots, in which the central horizontal line in each box represents the median, the boxes span the interquartile range, and the whiskers represent $90 \%$ confidence intervals. Outliers are incidence rates more than 1.5 times the length of the box. In these analyses, $p$-values $<0.05$ were considered statistically significant. The sensitivity and specificity of distinguishing between the two groups using cut-off drowning values was estimated using a receiver operating characteristic (ROC) analysis. The areas under the curve were calculated and analyzed using a one-tailed test. The optimal compromise between sensitivity and specificity was determined graphically.

\section{Results}

\subsection{TWC measurements}

The TWC in all organs ranged between $72.0-89.2 \%$ (median, 80.0\%). The brain and spleen showed markedly lower TWC levels than the other organs, with the spleen and kidney showing markedly lower levels than the lung (Fig. 1). The differences in the TWC measurements between the bilateral sites of individual organs were $0.0-8.09 \%$ (median, $1.31 \%$ ). These values ranged from $0.0-13.3 \%$ (mean, $1.06 \%$ ) for the upper and lower lobes of the lung and $0.0-7.3 \%$ (median, $0.76 \%$ ) for the kidneys. In all cases, the TWC was lower for the brain and spleen than for the other viscera $(p<0.0001)$, and was slightly lower for the kidney than for the lung (Table 3$)$. The bilateral 
correlations were $r=0.687(p<0.0001)$ and $r=0.752(p<0.0001)$ for the upper and lower lobes of the lungs, respectively, and $r=0.746(p<0.0001)$ for the kidneys.

Organ weights, the details of which are shown in Table 2, were then compared with TWC. Moderate correlations were found between the TWC and organ weights corrected by body height (the ratio of organ weight to body height) for the upper lobes of each lung (left: $r=0.396, p<$ 0.0001; right: $r=0.375, p<0.0001)$. The correlations were weaker for the lower lobes (left: $r=$ 0.288, $p<0.0001$; right: $r=0.289, p<0.0001$ ) and kidneys (left: $r=0.152, p<0.01$; right: $r=$ 0.217, $p<0.001$ ), and no significant relationship was found in the brain and spleen. The TWC of all organs other than the brain showed a slight negative correlation with bilateral heart blood hematocrit values $(r=0.202-0.340, p<0.01-0.0001)$.

\subsection{Influences of postmortem interval, survival period, age, and gender}

No significant postmortem or survival-period dependencies were observed for the TWC of individual organs. The spleen TWC was greater for females (72.79-82.49; median, 78.38) than for males (76.25-82.46; median, 77.54; $p<0.0001)$, and the TWC of the brain and kidney showed slight to moderate negative correlations with age (brain: $r=0234, p<0.0001$; left kidney: $r=$ 0.274, $p<0.0001$; right kidney: $r=0.238, p<0.0001)$.

\subsection{Relationship with the cause of death}

\subsubsection{Lung}

The TWC of the bilateral lung upper lobes was significantly higher in the drowning than in the injury, asphyxia, fire fatality, fatal intoxication, hyperthermia, and acute cardiac death cases $(p<$ 0.0001-0.05) (Fig. 2a). In both the right and left lower lobes, the TWC was higher for the drowning 
than for the injury, asphyxia, fire fatality, fatal intoxication, hyperthermia, hypothermia, and acute cardiac death cases $(p<0.0001-0.05)$ (Fig. 2b). Among the drowning cases, the saltwater cases had markedly higher TWC levels than the bathtub cases in the lower lobe of the left lung $(p<$ 0.05) (Fig. 3a,b). Among the asphyxia cases, the hanging cases had lower TWC levels than the strangulation cases in the upper lobe of the right lung $(p<0.05)$ (Fig. 4a,b). The cut-off values (sensitivity and specificity) from the ROC analysis were estimated for discriminating between groups with higher and lower TWC levels as follows: upper lobe of the left lung, 82.86\% (0.719 and 0.795$)$ for the drowning group and $83.81 \%(0.900$ and 0.871$)$ for the saltwater drowning cases; upper lobe of the right lung, 81.99\% (0.750 and 0.704$)$ for the drowning group and $83.50 \%(0.800$ and 0.843 ) for the saltwater drowning cases; lower lobe of the left lung, $82.55 \%(0.813$ and 0.791$)$ for the drowning group and 84.01\% (0.900 and 0.918) for the saltwater drowning cases; and lower lobe of the right lung, $82.40 \%(0.750$ and 0.781$)$ for the drowning group and $82.95 \%(0.900$ and 0.803) for the saltwater drowning cases.

\subsubsection{Brain}

The brain TWC was higher in the hypothermia (cold exposure) than in the injury, asphyxia, fatal intoxication, and fire fatality cases $(p<0.05)$, and tended to be higher in the hyperthermia (heatstroke) cases (Fig. 5a). No significant differences were observed among the injury, asphyxia, fatal intoxication, or fire fatality subgroups $(p>0.05)$; however, the brain tended to show lower TWC levels in the saltwater compared with the freshwater and bathtub drowning cases (Fig. 5b).

\subsubsection{Kidney}

The kidney TWC was higher in the drowning and acute cardiac death groups than in the fatal 
intoxication, asphyxia, fire fatality, and hyperthermia cases $(p<0.0001-0.05)$ (Fig. 6a). Among the subgroups, the saltwater had lower TWC levels than the freshwater and bathtub drowning cases in the left kidney $(p<0.05)$ (Fig. 6b). Among the fire fatality cases, those with intermediate CO$\mathrm{Hb}$ levels (30-60\%) had higher TWC in the left kidney than those with high CO-Hb levels $(p<$ 0.05) (Fig. 6c). No significant differences were observed among the injury, mechanical asphyxia, and fatal intoxication subgroups $(p>0.05)$. However, in the asphyxia groups, the hanging cases tended to have lower TWC levels in the kidneys compared with the strangulation cases (Fig. 6d). Based on the ROC analysis, the cutoff values (sensitivity and specificity) for discriminating groups with higher and lower WTC levels were estimated as follows: left kidney, 80.69\% (0.656 and $0.613)$ for drowning and $80.29 \%(0.828$ and 0.513$)$ for acute cardiac death; and right kidney, $80.49 \%(0.625$ and 0.589$)$ for drowning and $80.26 \%(0.862$ and 0.573$)$ for acute cardiac death.

\subsubsection{Spleen}

In the spleen, no significant differences in the TWC were observed among the different causes of death (Fig. 7a), or among the injury, asphyxia, fatal intoxication, and fire fatality subgroups ( $p$ $>0.05)$. However, among the drowning subgroups, the saltwater cases had lower spleen TWC levels than the bathtub cases $(p<0.05)$ (Fig. 7b).

\section{Discussion}

The aim of this study was to investigate the relationship between the TWC of the lungs, brain, kidneys, and spleen among deceased individuals as a possible quantitative indicator of the pathophysiology of systemic water dynamics. 
The findings showed that the TWC levels of the lungs and kidneys in deceased patients were higher compared with those of the brain and spleen, consistent with circulatory failure. The correlation observed between TWC and organ weight in the lungs and kidneys showed that organ weights can be applied as TWC. The brain and spleen are considered to be uncorrelated because they are susceptible to conditions such as cerebral atrophy and splenomegaly. When the organs absorb water, the hematocrit value is expected to decrease. In the present study, decreases in hematocrit were observed against increases in TWC. Since the hematocrit value is influenced by the viscosity of the blood, organ edemas are more likely to occur when the viscosity of the blood is low.

The lungs showed significantly higher TWC levels in the drowning cases. Among the drowning subgroups, saltwater showed markedly higher TWC levels than bathtub cases. Among the asphyxia cases, strangulation had higher TWC levels in the lung than hanging cases. These results suggest that saltwater drowning is similar to hypoxia. ${ }^{15}$ Consistent with these findings, previous studies have suggested that the postmortem lung weight may depend on both the aspirated immersion medium involved in drowning cases ${ }^{16,17}$ and the acute respiratory distress and circulatory failure involved in fire fatalities. ${ }^{18}$

The kidneys showed a significantly higher TWC in the drowning and acute cardiac death groups. An increase in kidney TWC owing to cardiac disease is indicative of circulatory failure. Among the drowning subgroups, the saltwater cases tended to have lower TWC levels than the freshwater and bathtub cases. In the asphyxia groups, hanging tended to result in lower TWC levels in the kidney compared with strangulation. These results suggest that saltwater drowning is similar to ischemia in the kidney. ${ }^{19}$

In the brain and spleen, the TWC was lower compared with that of other organs, but no clear 
differences were observed among the different causes of death. It is possible that the TWC of the brain and spleen manifest as the final condition of a case, but further evidence is needed before drawing conclusions.

\section{Conclusion}

In conclusion, TWC can indicate lung edema resulting from water aspiration and/or circulatory failure, which could be useful in pathophysiological analyses to distinguish between saltwater and freshwater drowning cases. In addition, kidney TWC may be an indicator of circulatory failure. We therefore recommend the measurement of TWC because it is easy to perform and appears to be useful for evaluating the pathophysiology of systemic circulatory failure.

\section{Disclosures}

\section{Funding}

This research did not receive any specific grant from funding agencies in the public, commercial, or not-for-profit sectors.

\section{Competing interests}

No authors have any conflicts of interest to declare.

\section{Ethics statement}

This study was approved by the ethics review board of the Osaka City University Medical School. 


\section{Acknowledgments}

The authors are grateful to Dr. T. Michiue for the long-term collaboration and advice, especially the collaboration during the early stages of the present study.

\section{References}

1. Atherton JC. Regulation of fluid and electrolyte balance by the kidney. Anaesth Intensive Care Med. 2006;7:227-233.

2. Navas JP, Martinez-Maldonado M. Pathophysiology of edema in congestive heart failure. Heart Dis Stroke. 1993;2:325-329.

3. Wang Q, Ishikawa T, Michiue T, Zhu BL, Guan DW, Maeda H. Molecular pathology of pulmonary edema after injury in forensic autopsy cases. Int J Legal Med. 2012;126:875-882.

4. Wang Q, Ishikawa T, Michiue T, Zhu BL, Guan DW, Maeda H. Molecular pathology of brain edema after severe burns in forensic autopsy cases with special regard to the importance of reference gene selection. Int J Legal Med. 2013;127:881-889.

5. Wang Q, Ishikawa T, Michiue T, Zhu BL, Guan DW, Maeda H. Molecular pathology of pulmonary edema in forensic autopsy cases with special regard to fatal hyperthermia and hypothermia. Forensic Sci Int. 2013;228:137-141.

6. Chen JH, Quan L, Ishikawa T, Michiue T, Wang Q, Zhu BL, Maeda H. Postmortem lung weight with regard to survival time. Leg Med (Tokyo). 2009;11 Suppl 1:S238-240. 
7. Zhu BL, Quan L, Li DR, Taniguchi M, Kamikodai Y, Tsuda K, Fujita MQ, Nishi K, Tsuji T, Maeda H. Postmortem lung weight in drownings: A comparison with acute asphyxiation and cardiac death. Leg Med (Tokyo). 2003;5:20-26.

8. Hausmann R, Vogel C, Seidl S, Betz P. Value of morphological parameters for grading of brain swelling. Int J Legal Med. 2006;120:219-225.

9. Lee J, de Louw E, Niemi M, Nelson R, Mark RG, Celi LA, Mukamal KJ, Danziger J. Association between fluid balance and survival in critically ill patients. J Intern Med. 2015;277:468-477.

10. Michiue T, Ishikawa T, Kawamoto O, Sogawa N, Oritani S, Maeda H. Postmortem CT investigation of air/gas distribution in the lungs and gastrointestinal tracts of newborn infants: a serial case study with regard to still- and live birth. Forensic Sci Int. 2013;226:74-80.

11. Michiue T, Ishikawa T, Oritani S, Kamikodai Y, Tsuda K, Okazaki S, Maeda H. Forensic pathological evaluation of postmortem pulmonary CT high-density areas in serial autopsy cases of sudden cardiac death. Forensic Sci Int. 2013;232:199-205.

12. Radojevic N, Radnic B, Vucinic J, Cukic D, Lazovic R, Asanin B, Savic S. Mathematical model in post-mortem estimation of brain edema using morphometric parameters. J Forensic Leg Med. 2017;45:21-28.

13. Figueras J, Weil MH. Blood volume prior to and following treatment of acute cardiogenic pulmonary edema. Circulation. 1978;57:349-355.

14. Quan L, Ishikawa T, Michiue T, Li DR, Zhao D, Yoshida C, Chen JH, Komatsu A, Azuma Y, Sakoda S, Zhu BL. Analyses of cardiac blood cells and serum proteins with regard to cause of death in forensic autopsy cases. Leg Med (Tokyo). 2009;11 Suppl 1:S297-300.

15. Giammona ST. Drowning: pathophysiology and management. Curr Probl Pediatr. 1971;1:1- 
33.

16. Zhao D, Ishikawa T, Quan L, Michiue T, Yoshida C, Komatu A, Chen JH, Wang Q, Zhu B-L, Maeda H. Evaluation of pulmonary GLUT1 and VEGF mRNA levels in relation to lung weight in medicolegal autopsy cases. Leg Med (Tokyo). 2009;11 Suppl 1:S290-293.

17. Maeda H, Zhu B-L, Ishikawa T, Quan L, Michiue T, Bessho Y, Okazaki S, Kamikodai Y, Tsuda K, Komatsu A, Azuma Y. Analysis of postmortem biochemical findings with regard to the lung weight in drowning. Leg Med (Tokyo). 2009;11 Suppl 1:S269-272.

18. Zhu BL, Ishikawa T, Quan L, Oritani S, Li DR, Zhao D, Michiue T, Tsuda K, Kamikodai Y, Okazaki S, Maeda H. Possible factors contributing to the postmortem lung weight in fire fatalities. Leg Med (Tokyo). 2005;7:139-143.

19. Zhu BL, Ishida K, Taniguchi M, Quan L, Oritani S, Tsuda K, Kamikodai Y, Fujita MQ, Maeda H. Possible postmortem serum markers for differentiation between fresh-, saltwater drowning and acute cardiac death: a preliminary investigation. Leg Med (Tokyo). 2003;5:S298-301. 
Figure legends

Figure 1. Postmortem tissue water content (TWC) in all organs as a function of the cause of death.

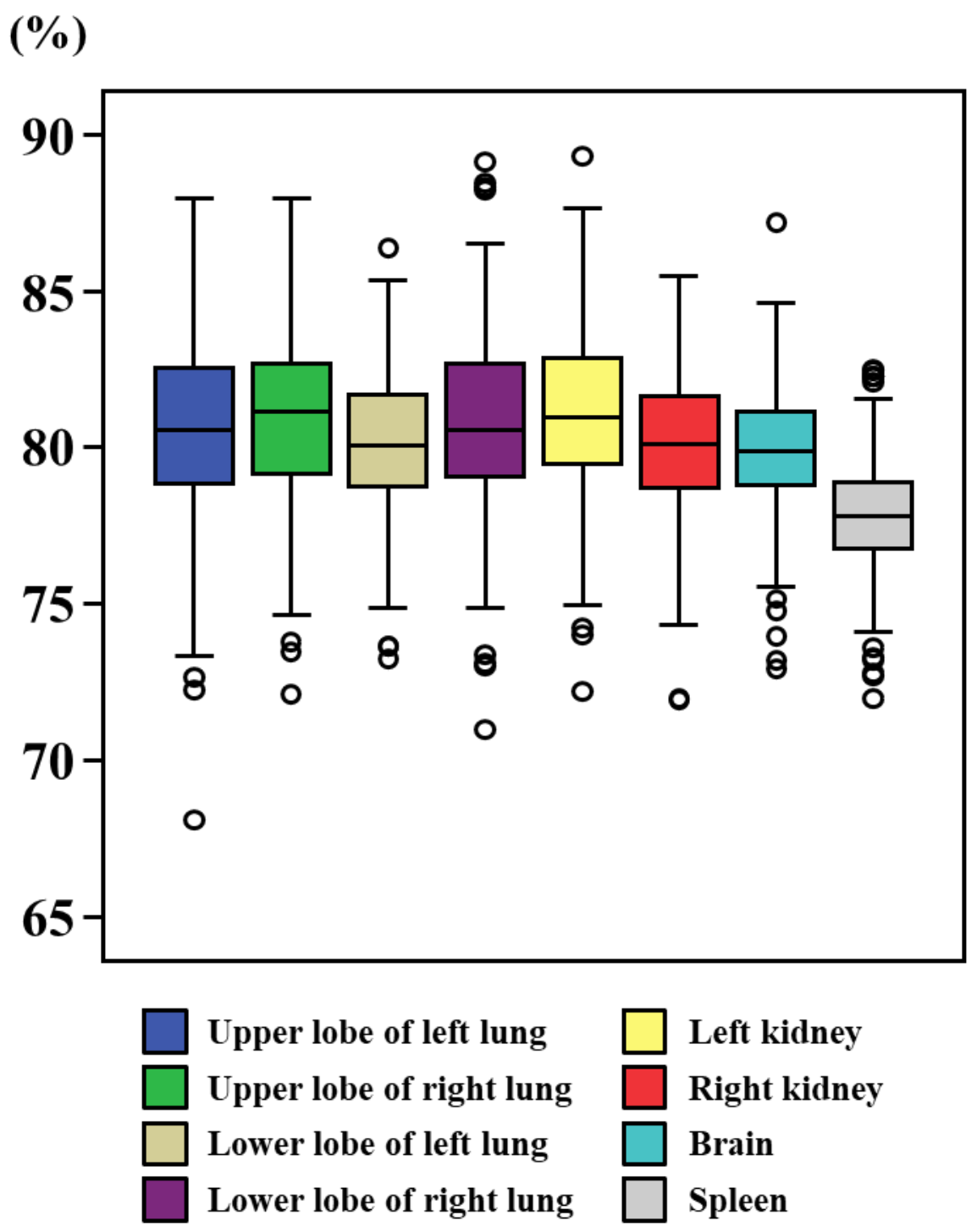


Figure 2. TWC in the lung with regard to the cause of death. (a) *Significantly higher: in the upper lobes of the lung, the drowning cases had significantly higher TWC compared with the injury, asphyxia, fire fatalities, fatal intoxication, hyperthermia and acute cardiac death cases $(p<0.0001-$ 0.05). (b) In the lower lobes of the lung, the drowning cases had higher TWC compared with the injury, asphyxia, fatal intoxication, fire fatality, hyperthermia, hypothermia, and acute cardiac death cases $(p<0.0001-0.05)$.

(\%) (a) Upper lobe of the lung

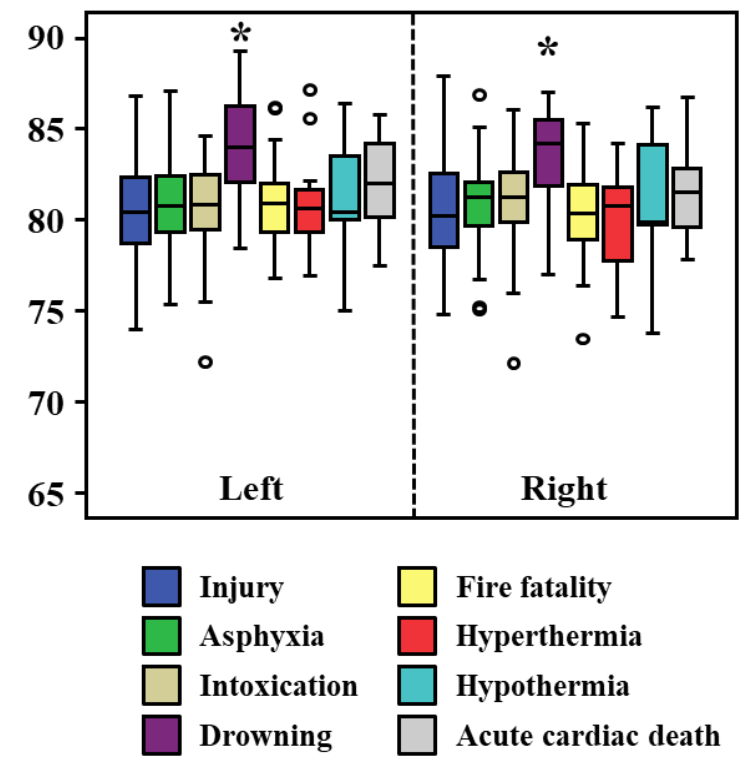

(b) Lower lobe of the lung

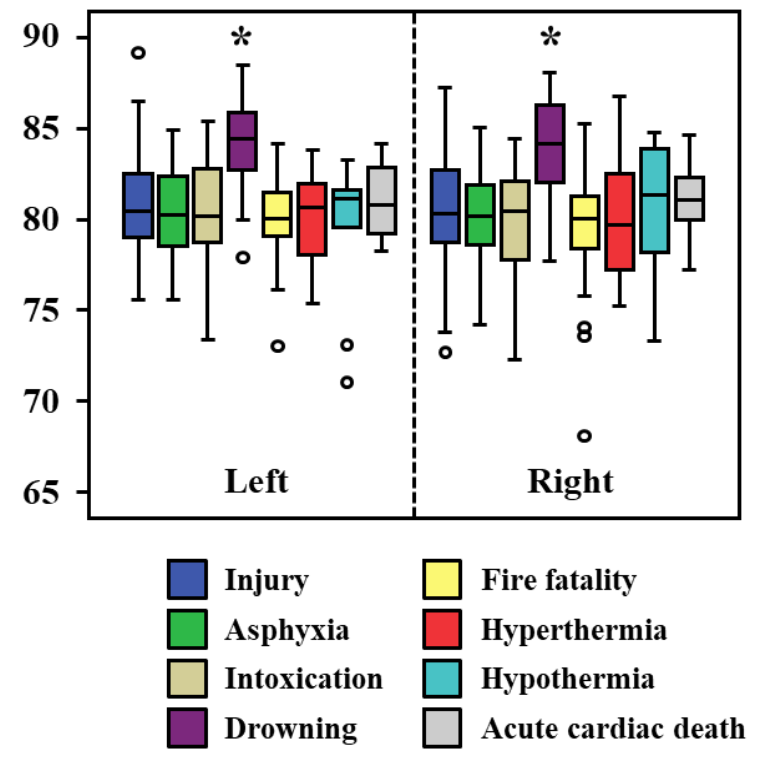


Figure 3. TWC in the upper (a) and lower (b) lobes of the lung in drowning cases. *Significantly higher: saltwater cases vs. bathwater cases in the lower lobe of the left lung $(p<0.05)$.
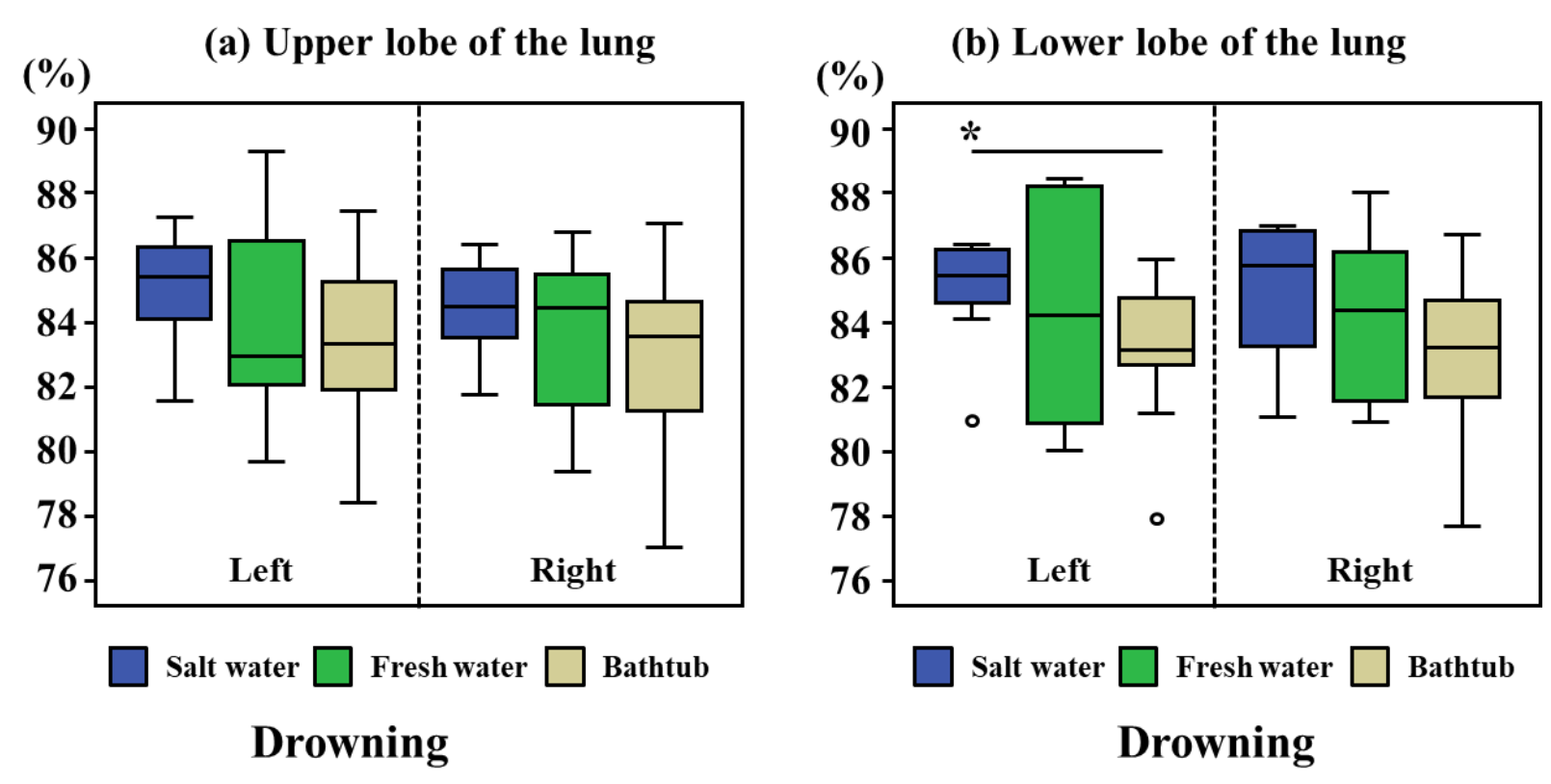
Figure 4. TWC in the upper (a) and lower (b) lobes of the lung in acute mechanical asphyxia cases. †Significantly lower: the hanging cases vs. the strangulation, and other asphyxia cases in the upper lobe of the right lung $(p<0.05)$.

(a) Upper lobe of the lung

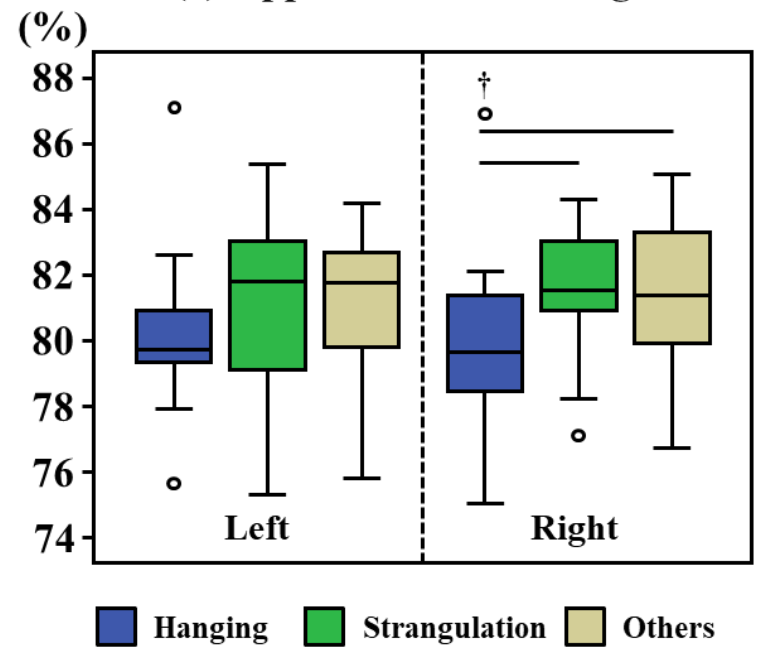

Asphyxia (b) Lower lobe of the lung

(\%)

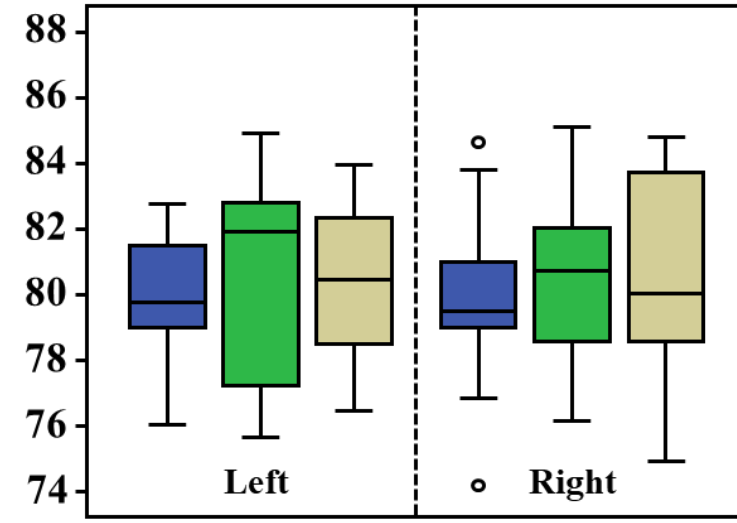

Hanging $\square$ Strangulation $\square$ Others Asphyxia 
Figure 5. TWC in the brain with regard to the cause of death. (a) *Significantly higher: hypothermia vs. injury, asphyxia, fatal intoxication, and fire fatality cases $(p<0.05)$. (b) TWC in the brain in drowning cases: the saltwater cases tended to have lower TWC than the freshwater and bathtub drowning cases.

(a)

(\%)

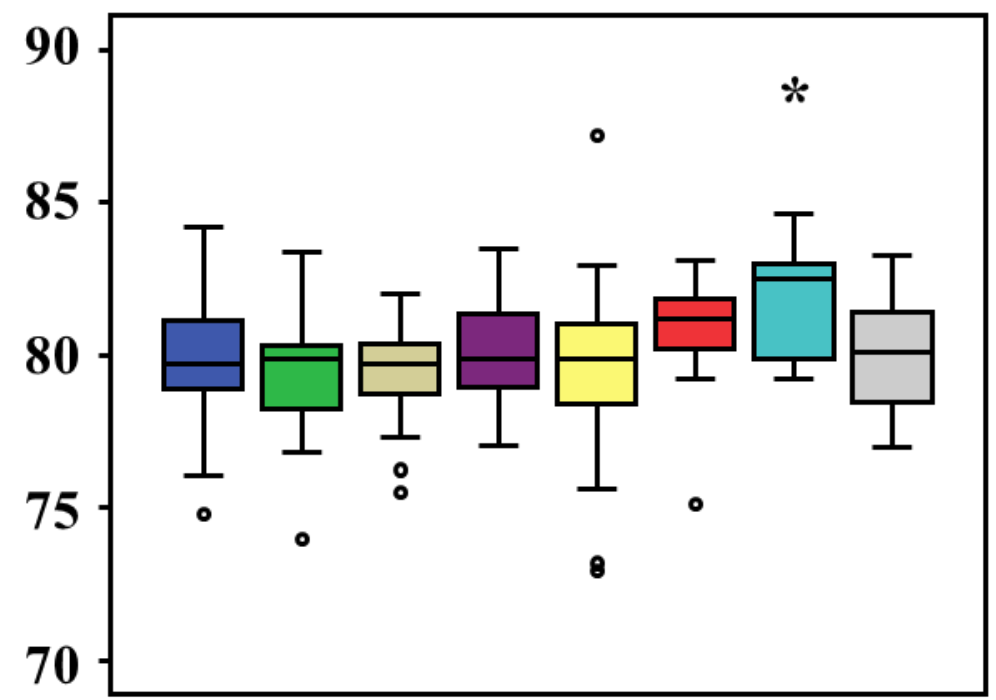

$\square$ Injury

$\square$ Asphyxia

$\square$ Intoxication

Drowning
Brain

- *

Fire fatality

Hyperthermia

Hypothermia

Acute cardiac death (b)

(\%) Drowning

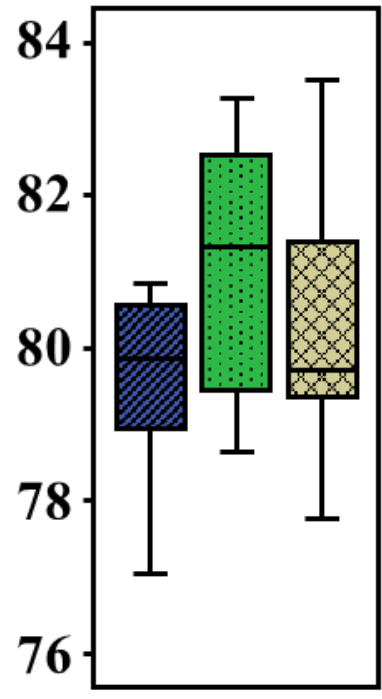

Salt water

Fresh water

Bathtub 
Figure 6. (a) TWC in the kidney with regard to the cause of death. Significantly higher: *drowning vs. fatal intoxication cases in both kidneys $(p<0.01)$ and $* *$ acute cardiac death vs. fatal intoxication, fire fatality, and hyperthermia cases in both kidneys $(p<0.0001-0.05)$. (b) TWC in the kidney in drowning cases. `Significantly lower: ${ }^{\dagger}$ Saltwater vs. freshwater and bathtub cases in the left kidney $(p<0.05)$. (c) TWC in the kidney in fire fatality cases. *Significantly higher: among the fire fatality cases, those with intermediate vs. high CO-Hb levels (left kidney: $p<0.05$ ). (d) TWC in the kidney in asphyxia cases. The hanging cases tended to have lower levels than the strangulation cases.

(a)

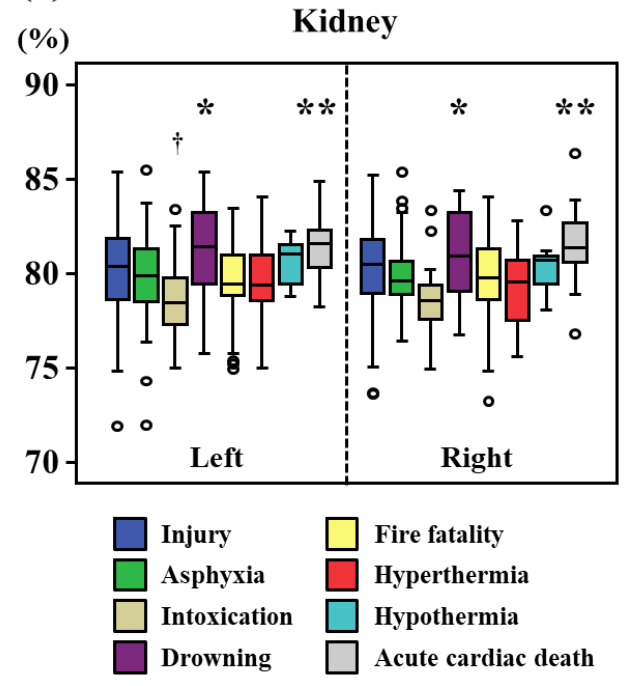

(c)

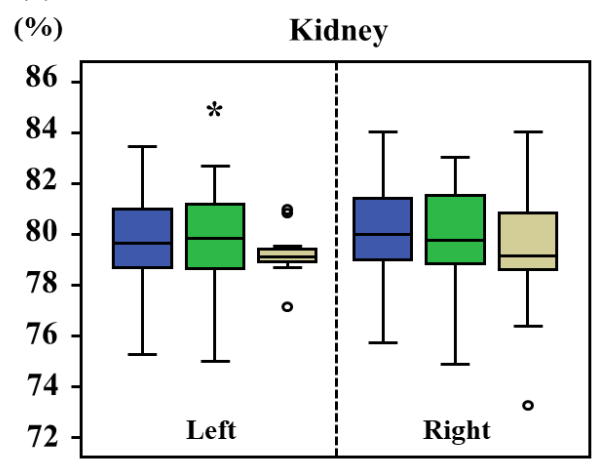

$\mathrm{CO}-\mathrm{Hb}<30 \% \square \mathrm{CO}-\mathrm{Hb}=30-60 \% \square \mathrm{CO}-\mathrm{Hb}>60 \%$

Fire fatality (b)

(\%) Kidney

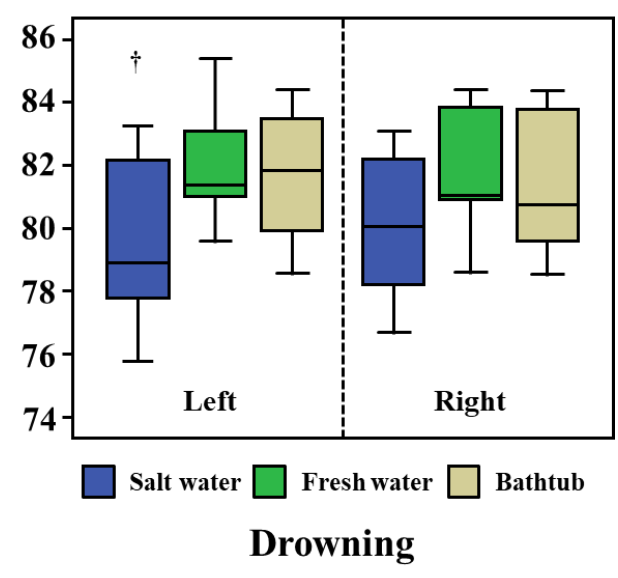

(d)

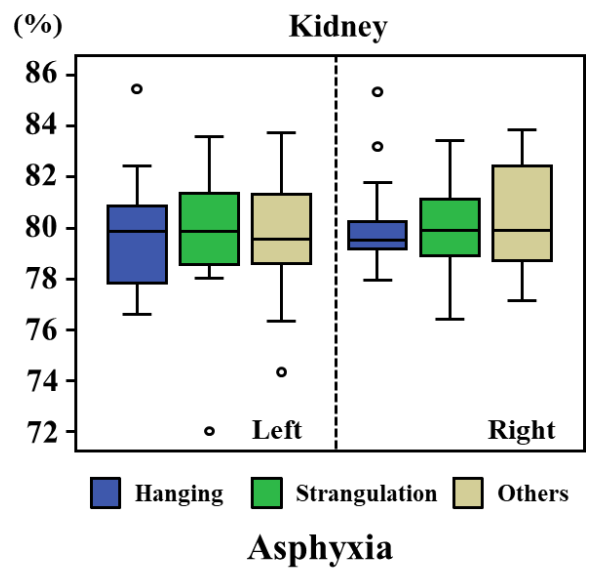


Figure 7. (a) TWC in the spleen with regard to the cause of death. No significant differences were observed among the causes of death. (b) TWC in the spleen in drowning cases.

†Significantly lower: saltwater vs. bathtub cases $(p<0.05)$.

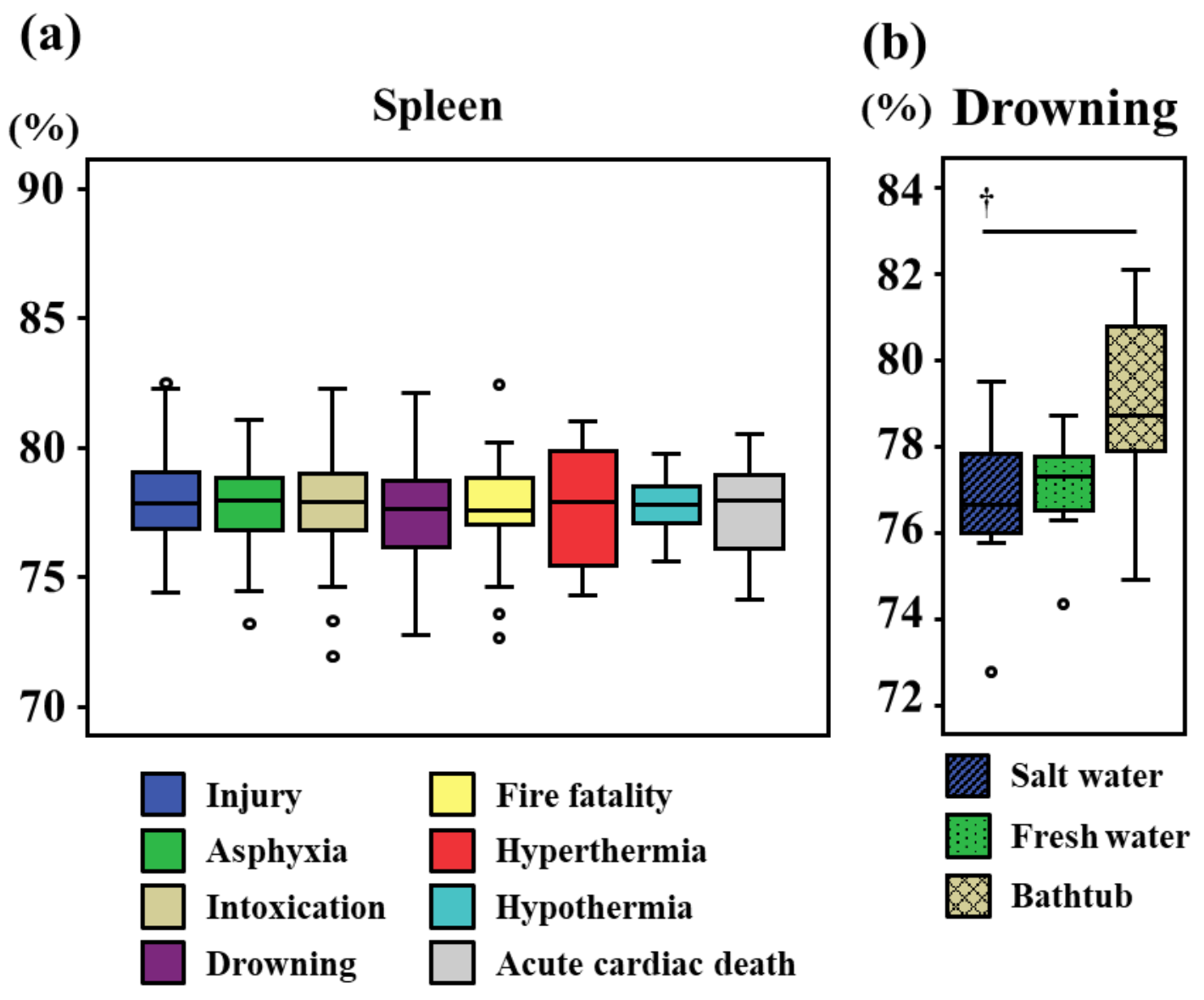




\section{Table legends}

Table 1

Case profiles $(\mathrm{n}=329)$.

\begin{tabular}{|c|c|c|c|c|}
\hline Cause of death & Male/female & Age (median) & $\begin{array}{l}\text { Survival time }(\mathrm{h}) \\
\text { (median) }\end{array}$ & $\begin{array}{l}\text { Postmortem time } \\
(\mathrm{h}) \\
(\text { median })\end{array}$ \\
\hline Injury & $68 / 24$ & $1-100(57)$ & $0.1-240(1.5)$ & $8-69(31)$ \\
\hline Head blunt injury & $28 / 11$ & $1-93(52)$ & $0.1-240(3.5)$ & $15-63(37)$ \\
\hline Non-head blunt injury & $25 / 7$ & $23-100(59)$ & $0.1-6(0.5)$ & $8-69(29)$ \\
\hline Sharp instrument injury & $15 / 6$ & $40-91(61)$ & $0.1-5(0.5)$ & $10-60(30)$ \\
\hline Asphyxia & $30 / 17$ & $23-87(61)$ & $0.1-480(0.5)$ & $8-65(31)$ \\
\hline Hanging & $13 / 4$ & $26-77(43)$ & $0.1-480(0.5)$ & $10-65(32)$ \\
\hline Strangulation & $7 / 9$ & $23-87(55)$ & $0.5-3(0.5)$ & $9-61(32)$ \\
\hline Others & $10 / 4$ & $30-75(66)$ & $0.5-3(0.5)$ & $8-57(25)$ \\
\hline Fatal intoxication & $12 / 15$ & $20-75(40)$ & $0.5-6(6)$ & $16-62(33)$ \\
\hline Metamphetamine & $7 / 6$ & $25-60(45)$ & $0.5-6(6)$ & $25-61(37)$ \\
\hline Psychotoropic drug & $3 / 6$ & $20-46(27)$ & $3.0-6(6)$ & $16-62(33)$ \\
\hline Others & $2 / 3$ & $29-75(37)$ & $0.5-6(6)$ & $18-39(29)$ \\
\hline Drowning & $20 / 12$ & $19-92(64.5)$ & $0.5-3(0.5)$ & $7-70(30)$ \\
\hline Salt water & $6 / 4$ & $19-79(64)$ & $0.5-3(0.5)$ & $7-70(41)$ \\
\hline Fresh water & $7 / 2$ & $34-87(61)$ & $0.5-3(0.5)$ & $20-62(33)$ \\
\hline Bathtub & $7 / 6$ & $49-92(66)$ & $0.5(0.5)$ & $17-61(25)$ \\
\hline Fire fatality & $52 / 25$ & 33-97 (71) & $0.5-1440(0.5)$ & $7-41(23)$ \\
\hline $\mathrm{CO}-\mathrm{Hb}<30 \%$ & $24 / 14$ & 33-97 (76) & $0.5-1440(0.5)$ & $11-38(20)$ \\
\hline $\mathrm{CO}-\mathrm{Hb}>30 \%,<60 \%$ & $20 / 4$ & $41-95(70)$ & $0.5-3(0.5)$ & $7-41(21)$ \\
\hline $\mathrm{CO}-\mathrm{Hb}>60 \%$ & $8 / 7$ & $42-91(67)$ & $0.5-3(0.5)$ & $12-41(25)$ \\
\hline Hyperthermia & $12 / 4$ & $39-95(72)$ & $0.5-6(6)$ & $15-65(31)$ \\
\hline Hypothermia & $6 / 3$ & $50-91(80)$ & $6.0-12.0(6)$ & $17-62(33)$ \\
\hline Acute cardiac death & $23 / 6$ & $19-92(62)$ & $0.1-12(0.5)$ & $6-56(23)$ \\
\hline Total & $223 / 106$ & $1-100(63)$ & $0.1-1440(0.5)$ & $6-70(29)$ \\
\hline
\end{tabular}


Table 2

Organ weights with regard to the cause of death $(n=329)$.

\begin{tabular}{|c|c|c|c|c|c|c|}
\hline Cause of death & $\begin{array}{l}\text { Left lung } \\
\text { (g) } \\
\text { (median) }\end{array}$ & $\begin{array}{l}\text { Right lung } \\
\text { (g) } \\
\text { (median) }\end{array}$ & $\begin{array}{l}\text { Left kidney } \\
(\mathrm{g}) \\
\text { (median) }\end{array}$ & $\begin{array}{l}\text { Right kidney } \\
\text { (g) } \\
\text { (median) }\end{array}$ & $\begin{array}{l}\text { Brain }(g) \\
\text { (median) }\end{array}$ & $\begin{array}{l}\text { Spleen } \\
(\mathrm{g}) \\
\text { (median) }\end{array}$ \\
\hline Injury $(\mathrm{n}=92)$ & $\begin{array}{l}65-1230 \\
(400)\end{array}$ & $\begin{array}{l}105-1330 \\
(482.5)\end{array}$ & $\begin{array}{l}36.8-310 \\
(140)\end{array}$ & $\begin{array}{l}20-255 \\
(127.5)\end{array}$ & $\begin{array}{l}955-1660 \\
(1315)\end{array}$ & $\begin{array}{l}16.8-210 \\
(80)\end{array}$ \\
\hline Asphyxia $(n=47)$ & $\begin{array}{l}230-905 \\
(470)\end{array}$ & $\begin{array}{l}235-1230 \\
(565)\end{array}$ & $\begin{array}{l}22.5-250 \\
(135)\end{array}$ & $\begin{array}{l}75-230 \\
(135)\end{array}$ & $\begin{array}{l}855-1690 \\
(1345)\end{array}$ & $\begin{array}{l}25-370 \\
(110)\end{array}$ \\
\hline Fatal intoxication $(\mathrm{n}=27)$ & $\begin{array}{l}240-910 \\
(485)\end{array}$ & $\begin{array}{l}335-1060 \\
(590)\end{array}$ & $\begin{array}{l}95-215 \\
(145)\end{array}$ & $\begin{array}{l}85-205 \\
(130)\end{array}$ & $\begin{array}{l}1170-1635 \\
(1335)\end{array}$ & $\begin{array}{l}25-345 \\
(105)\end{array}$ \\
\hline Drowning $(\mathrm{n}=32)$ & $\begin{array}{l}280-840 \\
(550)\end{array}$ & $\begin{array}{l}315-890 \\
(632.5)\end{array}$ & $\begin{array}{l}60-255 \\
(145)\end{array}$ & $\begin{array}{l}80-205 \\
(145)\end{array}$ & $\begin{array}{l}910-1540 \\
(1300)\end{array}$ & $\begin{array}{l}20-165 \\
(77.5)\end{array}$ \\
\hline Fire fatality $(\mathrm{n}=77)$ & $\begin{array}{l}59.5-945 \\
(400)\end{array}$ & $\begin{array}{l}70.5-1115 \\
(510)\end{array}$ & $\begin{array}{l}40-285 \\
(130)\end{array}$ & $\begin{array}{l}45-260 \\
(120)\end{array}$ & $\begin{array}{l}915-1505 \\
(1220)\end{array}$ & $\begin{array}{l}16.8-280 \\
(85)\end{array}$ \\
\hline Hyperthermia $(\mathrm{n}=16)$ & $\begin{array}{l}275-925 \\
(385)\end{array}$ & $\begin{array}{l}295-1040 \\
(520)\end{array}$ & $\begin{array}{l}40-285 \\
(130)\end{array}$ & $\begin{array}{l}57.1-205 \\
(117.5)\end{array}$ & $\begin{array}{l}1035-1560 \\
(1265)\end{array}$ & $\begin{array}{l}26.6-420 \\
(65)\end{array}$ \\
\hline Hypothermia $(\mathrm{n}=9)$ & $\begin{array}{l}185-710 \\
(345)\end{array}$ & $\begin{array}{l}190-1150 \\
(380)\end{array}$ & $\begin{array}{l}75-190 \\
(100)\end{array}$ & $\begin{array}{l}80-215 \\
(95)\end{array}$ & $\begin{array}{l}1150-1430 \\
(1305)\end{array}$ & $\begin{array}{l}25-100 \\
(65)\end{array}$ \\
\hline Acute cardiac death $(n=29)$ & $\begin{array}{l}220-1155 \\
(560)\end{array}$ & $\begin{array}{l}290-1350 \\
(700)\end{array}$ & $\begin{array}{l}80-310 \\
(160)\end{array}$ & $\begin{array}{l}65-325 \\
(160)\end{array}$ & $\begin{array}{l}1055-1580 \\
(1340)\end{array}$ & $\begin{array}{l}45-340 \\
(125)\end{array}$ \\
\hline Total & $\begin{array}{l}59.5-1230 \\
(450)\end{array}$ & $\begin{array}{l}70.5-1350 \\
(535)\end{array}$ & $\begin{array}{l}22.5-310 \\
(145)\end{array}$ & $\begin{array}{l}20-325 \\
(130)\end{array}$ & $\begin{array}{l}855-1690 \\
(1295)\end{array}$ & $\begin{array}{l}16.8-420 \\
(90)\end{array}$ \\
\hline
\end{tabular}


Table 3

Ranges of water contents of the lung, brain, kidney, and spleen.

\begin{tabular}{|c|c|c|c|c|c|c|}
\hline Organ & & & $\begin{array}{l}\text { Minimum } \\
(\%)\end{array}$ & $\begin{array}{c}\text { Maximum } \\
(\%)\end{array}$ & $\begin{array}{c}\text { Median } \\
(\%)\end{array}$ & $\begin{array}{c}\text { Mean } \\
(\%)\end{array}$ \\
\hline \multirow{4}{*}{ Lung } & \multirow{2}{*}{ Left } & $\begin{array}{l}\text { Upper } \\
\text { lobe }\end{array}$ & 72.23 & 89.29 & 80.98 & 81.16 \\
\hline & & $\begin{array}{l}\text { Lower } \\
\text { lobe }\end{array}$ & 71.00 & 89.15 & 80.60 & 80.76 \\
\hline & \multirow{2}{*}{ Right } & $\begin{array}{l}\text { Upper } \\
\text { lobe }\end{array}$ & 72.13 & 87.93 & 81.14 & 80.97 \\
\hline & & $\begin{array}{l}\text { Lower } \\
\text { lobe }\end{array}$ & 68.11 & 88.02 & 80.53 & 50.64 \\
\hline \multirow{2}{*}{ Kidney } & Left & & 71.95 & 85.49 & 81.10 & 80.06 \\
\hline & Right & & 73.26 & 86.37 & 80.04 & 80.15 \\
\hline Brain & & & 72.95 & 87.20 & 79.90 & 79.93 \\
\hline Spleen & & & 71.98 & 82.49 & 77.82 & 77.83 \\
\hline Total & & & 68.11 & 89.29 & 80.10 & 80.19 \\
\hline
\end{tabular}

Significantly lower: †kidney vs. lung $(p<0.0001-0.05)$. ${ }^{\dagger}$ Brain and spleen vs. other organs $(p<$ $0.0001)$. 